\title{
ELASTOPLASTIC INDENTATION OF UNSATURATED SOILS USING A RIGID CYLINDER
}

\author{
JAVADGHORBANI $^{*}$ AND JAYANTHA KODIKARA ${ }^{\dagger}$ \\ * ARC Smart Pavements Hub \\ Dept. of Civil Engineering \\ Monash University, VIC 3800, Australia \\ e-mail: javad.ghorbani@monash.edu \\ ${ }^{\dagger}$ ARC Smart Pavements Hub \\ Dept. of Civil Engineering \\ Monash University, VIC 3800, Australia \\ email: jayantha.kodikara@monash.edu
}

Key words:Unsaturated Soils, Plasticity, Contact Mechanics, Finite Element Method, Soil Dynamics, Coupled Problems.

Abstract.We develop a fully coupled finite element solution for elastoplastic indentations of unsaturated granular soils by a rigid cylinder by using a mortar-type contact algorithm. In the presented solution, we have employed an advanced constitutive model that allows the inclusion of the effect of matric suction and induced anisotropy in the problem. Several numerical examples in both static and dynamic scenarios are provided for validation and demonstrating the capabilities of the presented framework.

\section{INTRODUCTION}

Modelling the interaction between a rigid cylinder and multiphase porous media has several applications such as enhancement of the pipe installation methods and the compaction processes by using static, vibratory, and oscillatory drums[23, 19].

These problems can be modelled by the finite element solution where a constitutive model is employed to describe plasticity inside the soil domain. A more comprehensive model includes computational contact algorithms which allow a more accurate representation of the interface physics. Models of such interactions that involve the use of computational contact algorithmsare limited to single-phase [19] and two-phase (saturated) soils[26]. These models cannot describe the response of unsaturated soils realistically. Due to the prevalence of unsaturated soils in engineering projects associated with compaction and onshore structures, novel finite element solutions to model interactions involving unsaturated soils are highly demanded [20, 14, 13].

This paper presents the details of such asolution by employing the framework of unsaturated soil dynamics. The plasticity of unsaturated soils is assumed to be affected by stress-induced anisotropy [6]. A mortar-type contact algorithm is also used to simulate the interaction between a cylinder and a half-space (soil). The paper also provides a brief 
discussion of the finite element framework. Moreover, the paper presents the results of several simulations with the proposed framework fordemonstrating the capabilities of the proposed formulations.

\section{GENERAL SPECIFICATIONS}

By assuming solid (s), liquid (w), and gas (g), are continuously distributed throughout the unsaturated soil, the average density, $\rho$, is obtained from:

$$
\rho=(1-n) \rho_{s}+n S_{w} \rho_{w}+n\left(1-S_{w}\right) \rho_{g}
$$

where $n$ and $S_{w}$ are porosity and the degree of saturation. Additionally, $\rho_{s}, \rho_{w}$, and $\rho_{g}$ are the density of the solid, water, and air, respectively. We consider the Bishop's parameter equal to the degree of saturation $[25,11]$. Hence, by taking $\boldsymbol{\sigma}$ and $\boldsymbol{\sigma}^{\prime}$ respectivelyas the total and effective stress matrix, the following equation can be written

$$
\boldsymbol{\sigma}^{\prime}=\boldsymbol{\sigma}+p_{w} \mathbf{m}+\left(1-S_{w}\right) p_{c} \mathbf{m}
$$

\section{where $p_{w}$ is the water pressure and $p_{c}$ is suction defined as}

$$
p_{c}=p_{g}-p_{w}
$$
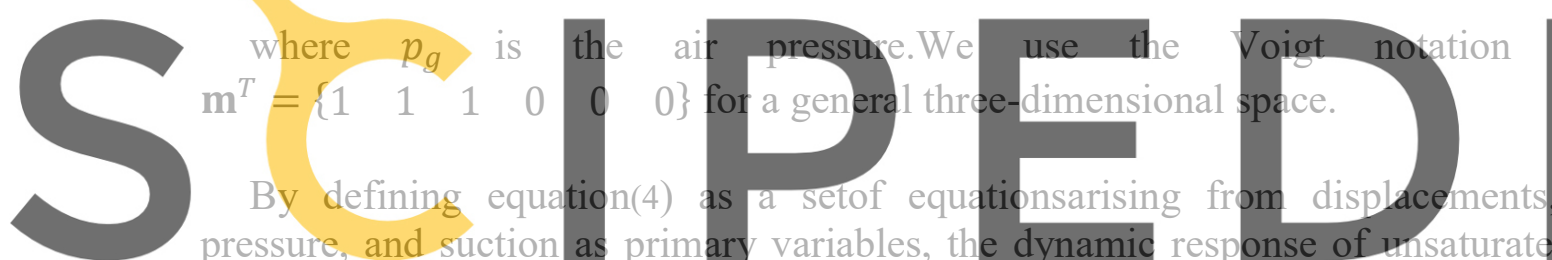
pressure, and suction as primary variables, the dynamic described as $[9,8]$

Register for free at https//www.scipedia.com to download the version without the watermark

$$
\begin{gathered}
\mathbf{M}_{\mathrm{u}} \ddot{\mathrm{U}}+\mathrm{C} \dot{U}+\int_{\Omega} \mathrm{B}^{T} \sigma^{\prime} \mathrm{d} \Omega-\mathrm{Q}_{\mathrm{w}} \mathrm{P}_{\mathrm{w}}-\mathrm{Q}_{\mathrm{c}} \mathrm{P}_{\mathrm{c}}=\mathrm{F}_{\mathrm{u}} \\
\mathbf{M}_{\mathbf{w}} \ddot{\mathbf{U}}+\mathbf{Q}_{\mathbf{w}}^{T} \dot{\mathbf{U}}+\mathbf{C}_{\mathbf{w w}} \dot{\mathbf{P}}_{\mathbf{w}}+\mathbf{C}_{\mathbf{w c}} \dot{\mathbf{P}}_{\mathbf{c}}+\mathbf{H}_{\mathbf{w w}} \mathbf{P}_{\mathbf{w}}+\mathbf{H}_{\mathbf{w c}} \mathbf{P}_{\mathbf{c}}=\mathbf{F}_{\mathbf{w}} \\
\mathbf{M}_{\mathbf{c}} \ddot{\mathbf{U}}+\mathbf{R}_{\mathbf{c}}^{\mathbf{T}} \dot{\mathbf{U}}+\mathbf{C}_{\mathbf{c w}} \dot{\mathbf{P}}_{\mathbf{w}}+\mathbf{C}_{\mathbf{c c}} \dot{\mathbf{P}}_{\mathbf{c}}+\mathbf{H}_{\mathbf{w c}}^{T} \mathbf{P}_{\mathbf{w}}+\mathbf{H}_{\mathbf{c c}} \mathbf{P}_{\mathbf{c}}=\mathbf{F}_{\mathbf{c}}
\end{gathered}
$$

where the superimposed dot denotes the time derivative of a quantity. The primary nodal variables and are defined by:

$$
\begin{gathered}
\mathbf{u}=\mathbf{N}_{\mathbf{u}} \mathbf{U} \\
p_{w}=\mathbf{N}_{\mathbf{p w}} \mathbf{P}_{\mathbf{w}} \\
p_{c}=\mathbf{N}_{\mathbf{p c}} \mathbf{P}_{\mathbf{c}}
\end{gathered}
$$

where $\mathbf{N}_{\mathbf{u}}, \mathbf{N}_{\mathbf{p w}}$ and $\mathbf{N}_{\mathbf{p c}}$ are the shape functions for the displacement, pore water pressure, and suction, respectively. 
In Equation (4) to ¡Error! No se encuentra el origen de la referencia., $\mathbf{B}, \mathbf{C}$, and $\mathbf{M}$ represent the strain-displacement, damping, and mass matrices, respectively.Also, $\mathbf{Q}$, and $\mathbf{H}$ denote the coupling, and flow matrices associated with permeability [9] (see Appendix A).

\subsection{Elasoplasticity}

The constitutive model that is used here (MUD-B) [6] is formulated within the framework of the bounding surface plasticityand has the following key features:

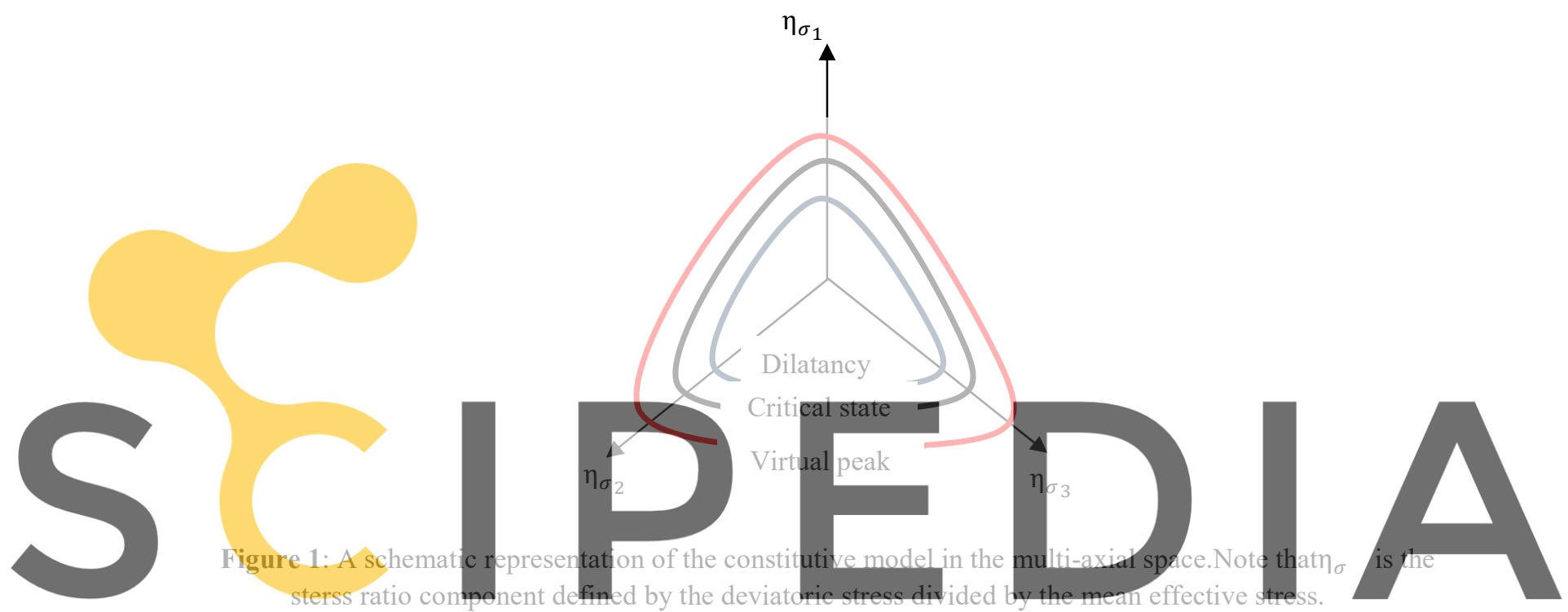

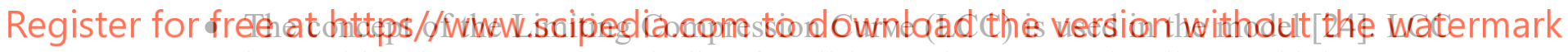
is considered as an asymptotic line for all isotropic compression lines at higher stress levels.

- The bi-logarithmic space $\left(\ln e-\ln p^{\prime}\right.$ where $e$ and $p^{\prime}$ are void ratio ad the mean effective stress, respectively) is used for describing the critical state line and volumetric hardening. The model also considers the effect of stress-induced anisotropy on volumetric hardening.

- Hardening/softening due to suction variations by using a combination of Bishop's effective stress and the "bonding variable" [4].

- A combination of isotropic and kinematic is used for simulating the behaviour of granular soil response to diverse and complex stress paths (e.g., cyclic loading).

- Two mapping rules are used for constructing "loading surfaces" from a reference bounding surface [6]. It is notable that loading surfaces are defined as auxiliary surfaces to describe the plasticity mechanism inside the bounding surface.

- The model is also formulated within the critical state theory by using the concept of the "state parameter" [1]. 
- The Soil Water Characteristics (SWCC) is a function of both matric suction and the void ratio by using a modified suction, $p_{c}^{*}$ defined as follows $p_{c}^{*}=p_{c} e^{\Omega \prime}$, where $\Omega^{\prime}$ is a material parameter $[9,7]$.

It should be noted that we ignored the small hysteresis of the SWCC in granular soils to avoid over-complication. A brief description of the key elements of the constitutive model and the SWCC is given inAppendix C. A schematic representation of the model in a multiaxial space is shown in Figure 1. The figure depicts three conceptual surfaces that are based on the presented equations for dilatancy, virtual peak, and the critical state and by using a Lode angle. It may be noted that changes in saturation degree or suction can result in the isotropic expansion of the surfaces of dilatancy and virtual peak.

\section{Treatment of interaction}

We assumed a plane strain condition in the problem for which quadratic six-node planestrain elements for displacement fields are used. These elements are coupled with two linear three-node elements developed for pore water pressure and suction. Due to the presence of quadratic elements, the so-called "node-to-segment" discretisation method will lead tothe loss of accuracy in calculating contact stresses. To enhance the accuracy, we have employed a mortar-type discretization[2].

The segments on one side of the contact other body involved mortar" are respectiv brief explanation of the to $[27,21]$.

The Kuhn-Tucker cent

of adhesion as follows

Register for free at https//www.scipedia.com to download the version without the watermark

$$
t_{n} \leq 0, \quad g_{n} \geq 0, \quad t_{n} \cdot g_{n}=0
$$

where $t_{n}$ is the contact stress and $g_{n}$ is the normal gap function defined in[27].

For the fully coupled framework, we use the penalty method over the Lagrange multiplier method toavoid addingextra degrees of freedom associated with the Lagrange multipliers. By assuming a non-frictional contact, the general form of the governing equations after applying the contact constraints on the contact segments are as follows[16].

$$
\begin{gathered}
\mathbf{M}_{\mathbf{u}} \ddot{\mathbf{U}}+\mathbf{C} \dot{\mathbf{U}}+\mathbf{K U}+\bigcup_{i=1}^{n_{s}} \mathbf{K}_{N C_{i}}-\mathbf{Q}_{\mathbf{w}} \mathbf{P}_{\mathbf{w}}-\mathbf{Q}_{\mathbf{c}}^{*} \mathbf{P}_{\mathbf{c}}=\mathbf{F}_{\mathbf{u}}+\bigcup_{i=1}^{n_{s}} \mathbf{F}_{N C_{i}} \\
\mathbf{M}_{\mathbf{w}} \ddot{\mathbf{U}}+\mathbf{Q}_{\mathbf{w}}^{T} \dot{\mathbf{U}}+\mathbf{C}_{\mathbf{w w}} \dot{\mathbf{P}}_{\mathbf{w}}+\mathbf{C}_{\mathbf{w c}} \dot{\mathbf{P}}_{\mathbf{c}}+\mathbf{H}_{\mathbf{w w}} \mathbf{P}_{\mathbf{w}}+\mathbf{H}_{\mathbf{w c}} \mathbf{P}_{\mathbf{c}}=\mathbf{F}_{\mathbf{w}} \\
\mathbf{M}_{\mathbf{c}} \ddot{\mathbf{U}}+\mathbf{R}_{\mathbf{c}}^{\mathbf{T}} \dot{\mathbf{U}}+\mathbf{C}_{\mathbf{c w}} \dot{\mathbf{P}}_{\mathbf{w}}+\mathbf{C}_{\mathbf{c c}} \dot{\mathbf{P}}_{\mathbf{c}}+\mathbf{H}_{\mathbf{w c}}^{T} \mathbf{P}_{\mathbf{w}}+\mathbf{H}_{\mathbf{c c}} \mathbf{P}_{\mathbf{c}}=\mathbf{F}_{\mathbf{c}}
\end{gathered}
$$

where $\mathbf{K}_{N C_{i}}$ and $\mathbf{F}_{N C_{i}}$ are the stiffness matrix and the force vector arising from segments that are in contact. Also, $n_{s}$ is the number of contact segments. To achieve additional control 
on numerical damping, the generalised- $\alpha$ method is used for time integration of the global equations $[5,11,10]$.

\section{NUMERICAL EXAMPLES}

In all simulations, the soil domain has a length and height of $3 \mathrm{~m}$ anda width of $3 \mathrm{~m}$. Note that because of the symmetry, only half of the domain is modelled. The soil domain is discretised by 3157 elements and 6551 nodes. Also, the side boundaries are not free to move horizontally, and the bottom boundary cannot move vertically. In the case of dynamic analysis, absorbing boundaries are used [12] for the side and bottom boundaries. Furthermore, unless stated otherwise, the surface allows drainage, and a diameter of $1.2 \mathrm{~m}$ is selected for the rigid cylinder in all simulations.

\subsection{Static interaction}

We first validate the developed framework against the Hertzian solution developed for the contact of a rigid cylinder and a half-space. The theoretical solution is developed for cases where no excess water and air pressures can occur. To enforce this condition, a sufficiently large and uniform time step of $10^{6} \mathrm{~s}$ is used in the analysis. The initial water pressure and suction of $0 \mathrm{kPa}$ are prescribed to the domain. Also, the mass of the cylinder is set to 7 tonnes $/ \mathrm{m}$. The simulation is performed by considering an elastic modulus $(E)$ of $100 \mathrm{MPa}$ and a Poisson's ratio $(v)$ of 0.3 .
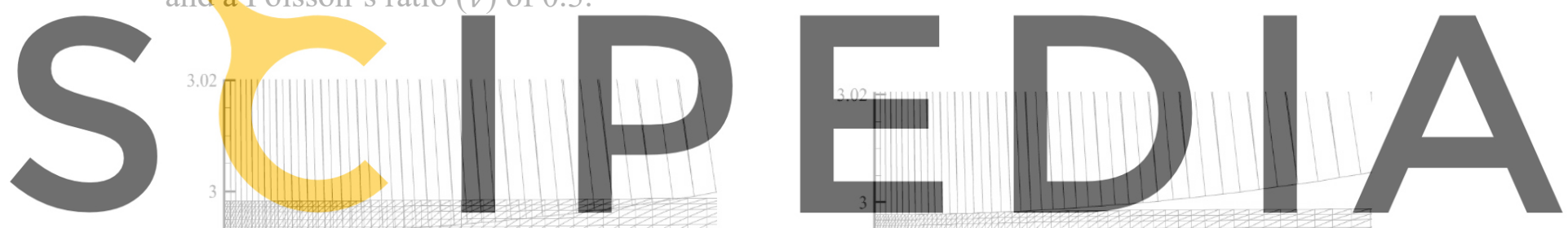

Register for free at https//www.scipedia.com to c

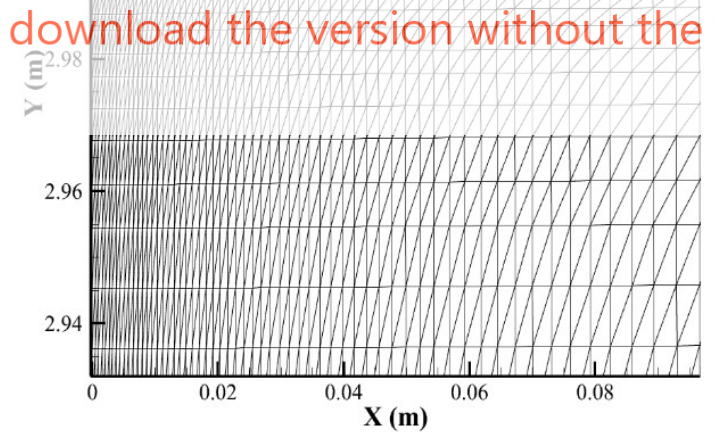

a)

b)

Figure 2: a) Cylinder-soil interaction with penalty coefficient being set to a) $\left.10^{5} \mathrm{~b}\right) 10^{7}$.

Figures 2 and 3 demonstrate the influence of the penalty coefficient on the prediction. It is notable that to fully enforce the condition of impenetrability, the penalty coefficient should be infinity. In the context of numerical simulations, selecting a very large value for penalty coefficient generally can lead to instability and ill-conditioning [27, 21]. Nonetheless, 
selecting a small value can also lead to a problem that is shown in Figure 2. a andFigure 2. b corresponding to a relatively small $\left(10^{5} \mathrm{kN} / \mathrm{m}^{3}\right)$ and a large penalty coefficient $\left(10^{7} \mathrm{kN} /\right.$ $\mathrm{m}^{3}$ ), respectively. It is seen that when the penalty coefficient is small, the rigid cylinder can considerably penetrate the non-mortar domain which leads to predicting a higher contact area and smaller stress value as shown in Figure 3.

The distributions of stress beneath the centre of the cylinder are shown in Figure 4. The numerical simulations are performed by settingthe penalty coefficient to $10^{7} \mathrm{kN} / \mathrm{m}^{3}$. Overall, good agreement is obtained with the theoretical solutions.

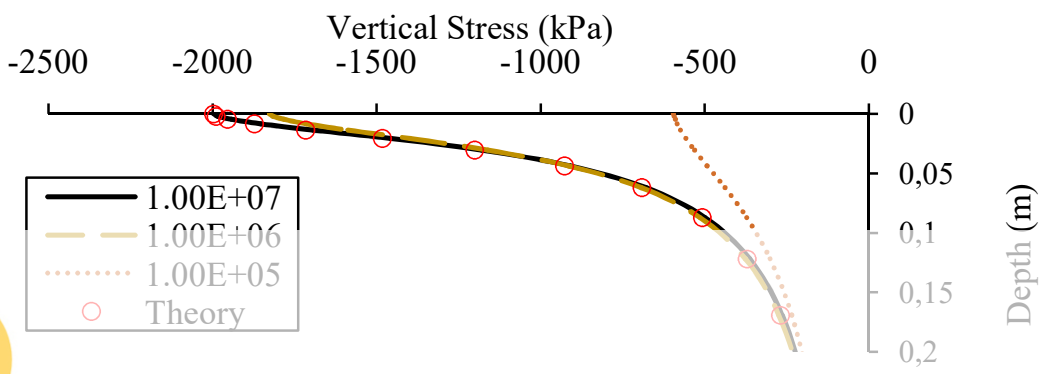

Figure 3:The influence of the penalty coefficient on the results.

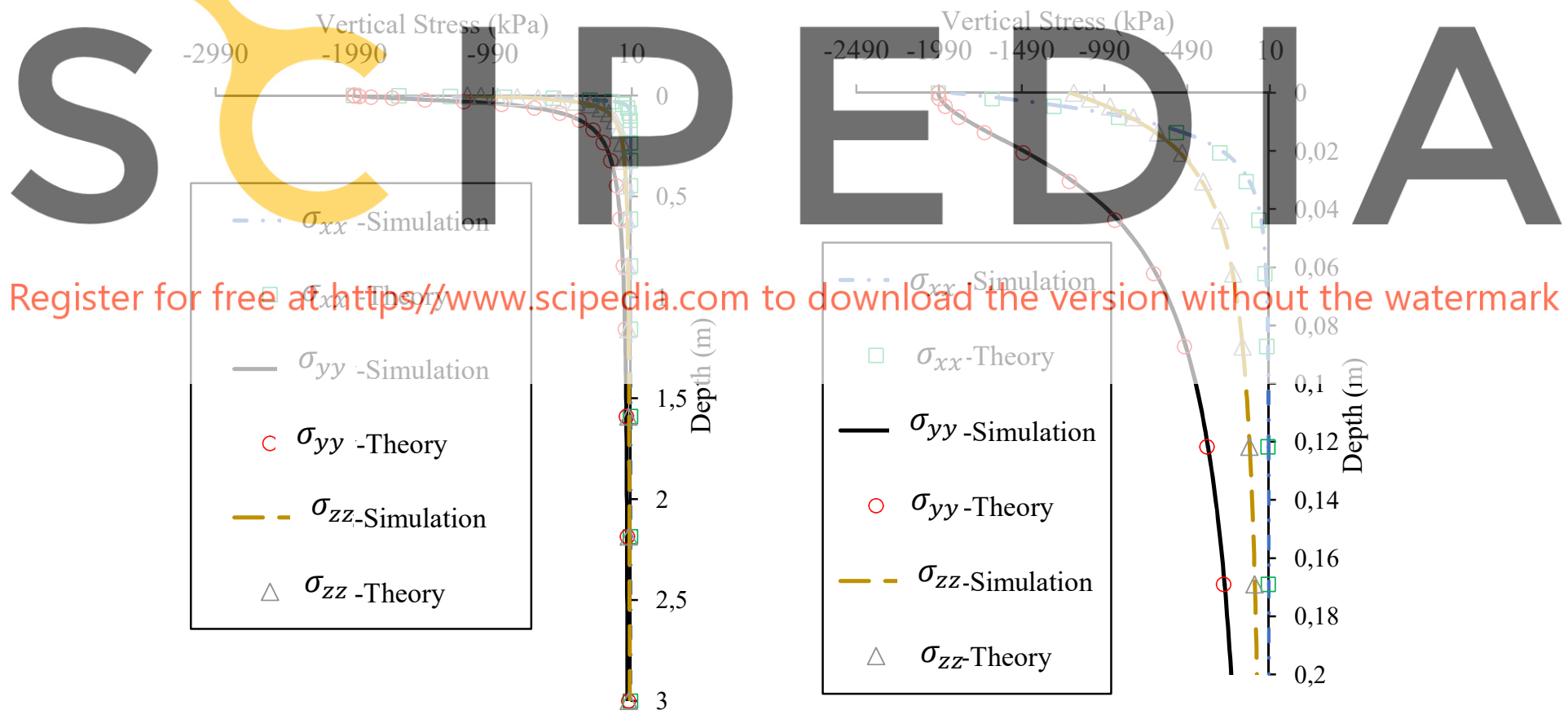

a)

b)

Figure 4: a) Stress with depth obtained from the simulation b) Enlarged version ofFigure 4.a.

In the next example, we investigate the case of elastoplastic interaction. The analysis is performed in two steps. First, the body force is applied,and next, the interaction is activated during a static step with a uniform time step of $10^{6} \mathrm{~s}$. 


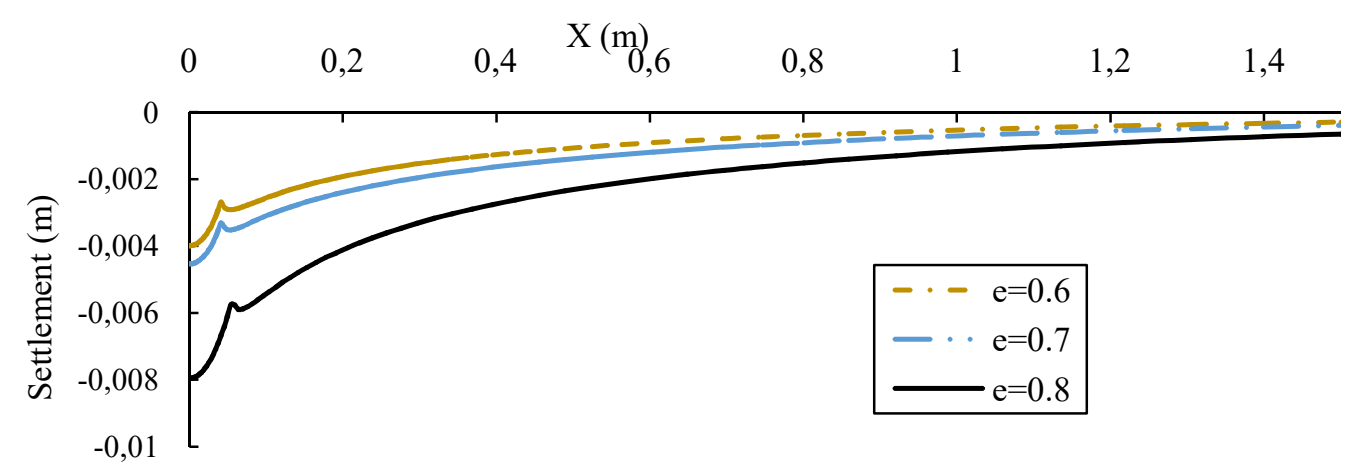

Figure 5: Ground deformations at the final step of the analysis.

The set of parameters that are used for solving all elastoplastic boundary value problems is from Toyoura sand from[6] and the assumed SWCC parameters are given in Appendix A. The assumed parameters for the Soil Water Characteristic Curve are given in Appendix A.

The ratio of horizontal to vertical stress is set to 0.4 and the penalty coefficient is $10^{7} \mathrm{kN} /$ $m^{3}$.All the analyses are performed at the initial moisture content of $14 \%$. In the loading step, the cylinder with the same weight as the previous example is statically placed on the soil with different initial void ratios of $0.6,0.7$, and 0.8 .Figure 5.a depicts the profile of the surface at the end of the analysis where the static equilibrium is achieved. The figure shows that the indentation depth decre

\subsection{Dynamic interadion}

We use a model with a geometry similar to
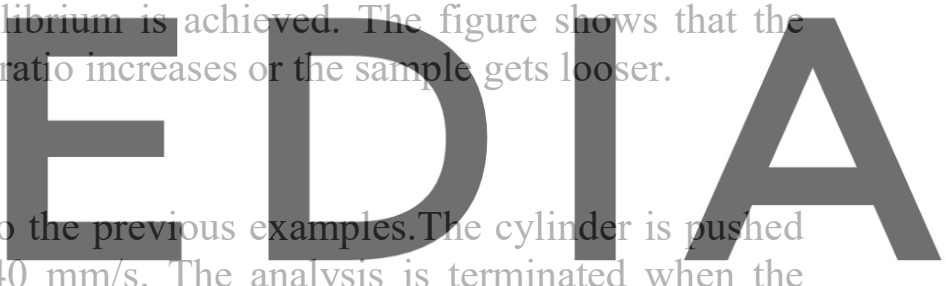

into the ground with an initial velocity of $40 \mathrm{~mm} / \mathrm{s}$. The analysis is terminated when the

Register for Iree at the cylinder becomes zero.

segments are in contact with the cylinder. The soil has an initial velocity of 0.6 and a suction of $10.8 \mathrm{kPa}$ and water pressure of $-10.8 \mathrm{kPa}$ are applied on the domain initially. The ratio of horizontal to vertical stress is set to 0.4 .

Figure 6.a demonstrates the acceleration/deceleration pattern of the cylinder during the impact. It is seen that the cylinder first accelerates, however as the ground reaction force increases during the indentation process, the deceleration begins, and the cylinder velocity finally reaches zero. The dynamic changes in the void ratio and suction are shown in Figure $6 . \mathrm{b}$ and $\mathrm{c}$ at $0.5 \mathrm{~m}$ below the surface. These figures show that suction decreases in response to the densification of soil.

We also assess the overall error in the predicted stresses $[15,17,6]$ using the following procedure

$$
E=\frac{\left\{\sum_{i=1}^{l}\left[\left(\boldsymbol{\sigma}_{r e f}^{\prime}-\boldsymbol{\sigma}^{\prime}\right)^{T}\left(\boldsymbol{\sigma}_{r e f}^{\prime}-\boldsymbol{\sigma}^{\prime}\right)\right]_{i}\right\}^{0.5}}{\left\{\sum_{i=1}^{l}\left[\left(\boldsymbol{\sigma}_{\text {ref }}^{\prime}\right)^{T}\left(\boldsymbol{\sigma}_{\text {ref }}^{\prime}\right)\right]_{i}\right\}^{0.5}}
$$




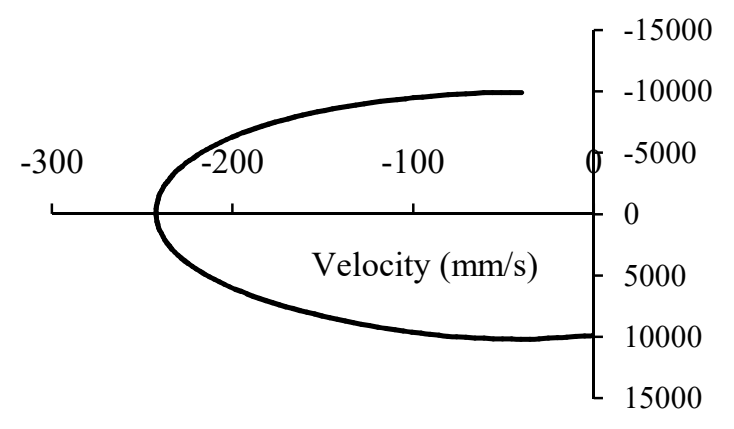

a)

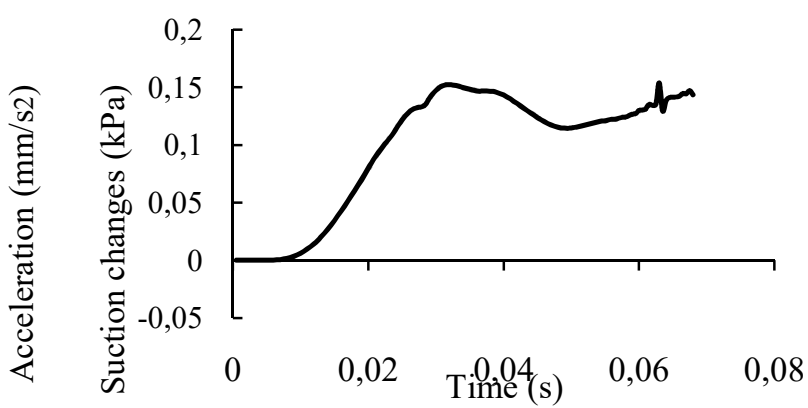

b)

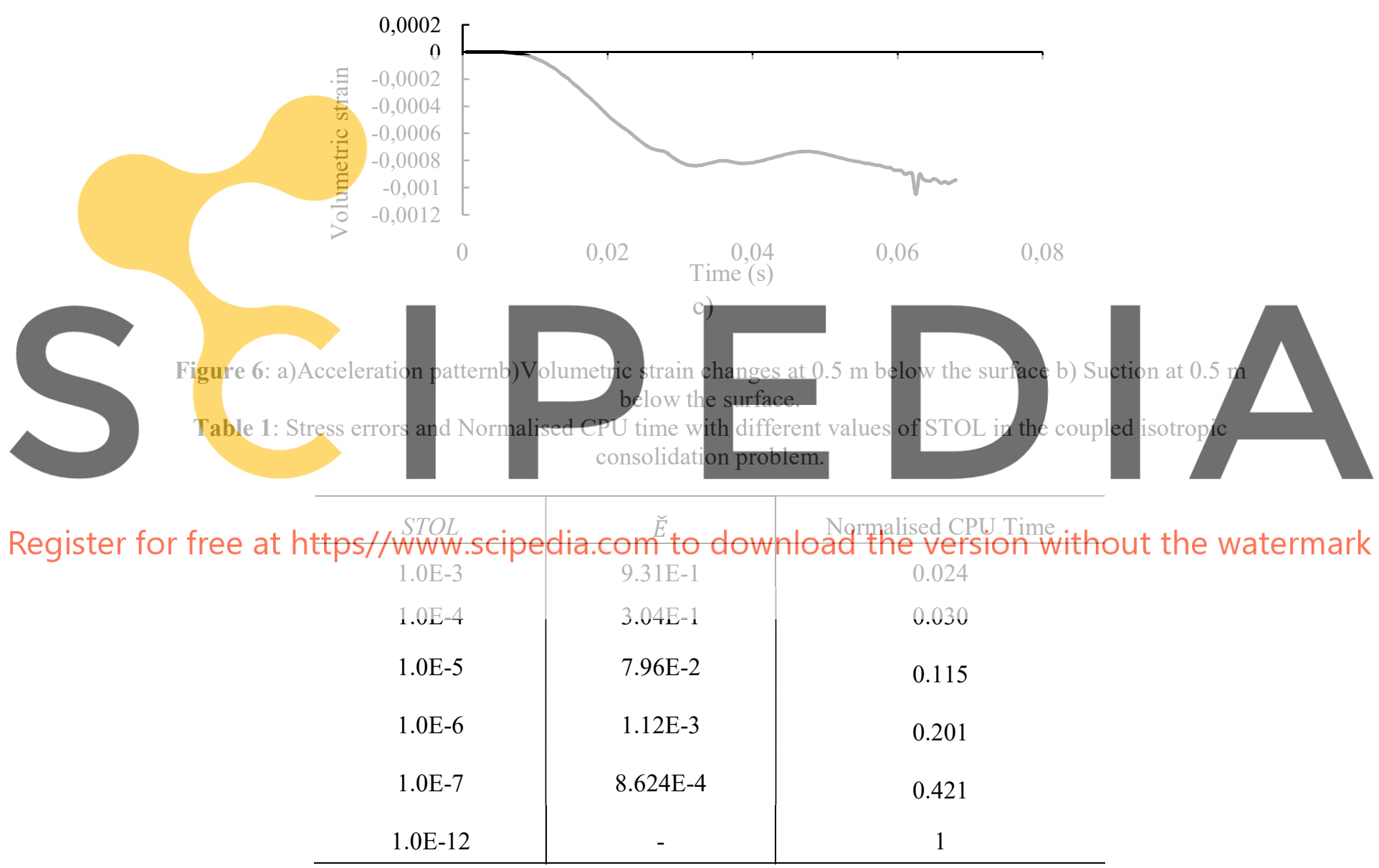

In Table $1, \boldsymbol{\sigma}_{r e f}^{\prime}$ denotes the reference stress components computed by adopting a very tight stress tolerance, $S T O L$, of $10^{-12}$, the subscript $i$ represents the $i$ th integration point in the mesh and $l$ is the total number of integration points. The results of the error assessment and the required computational times for the analyses with different values of STOL show that a tighter integration scheme generally leads to less error. Nonetheless, the analysis time can significantly increase when a value ofless than $1.0 \mathrm{E}-4$ is selected for STOL. The CPU times have been normalised by the CPU time corresponding to the analysis with $S T O L=10^{-12}$. 


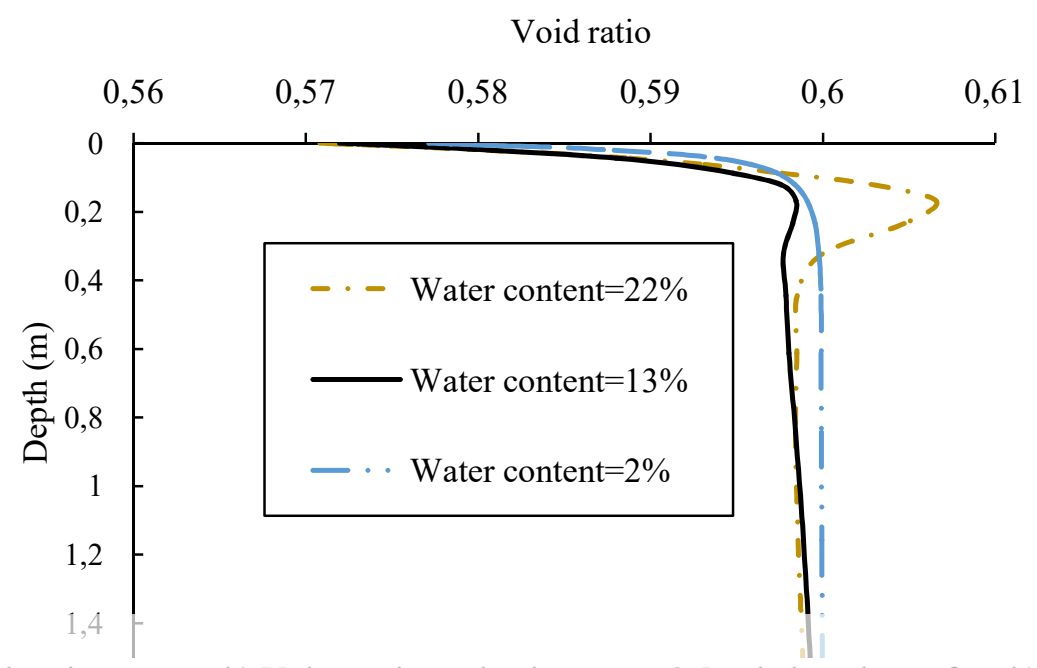

Figure 7: a)Acceleration pattern b) Volumetric strain changes at $0.5 \mathrm{~m}$ below the surface b) Suction at $0.5 \mathrm{~m}$ below the surface.

Figure 7 demonstrates the model prediction of void ratio changes beneath the centre of the impact when the moisture content of the soil changes. The results from using two extreme values of water content (22\% and 13\% corresponding to very dry and nearly saturated states)are compared with that with a water content of $13 \%$. For the case with the water content of $2 \%$, the graph shows that the level of densification is low

densification level is lower water content of $13 \%$. A $22 \%$. Such an observation is curves" that suggest genera the generated excess wate
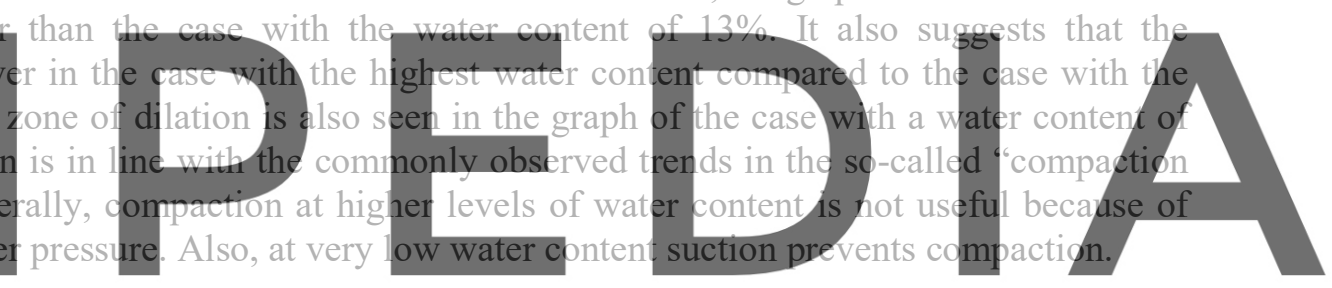

Register for free at https//Www.scipedia.com to download the version without the watermark The formulations of a mortar-type contact algorithm for unsaturated soil dynamics have been presented.

- $\quad$ The model is validated against theoretical solution and its performance are assessed by conducting different analyses in static and dynamic condition.

- A sensitivity analysis is performed on the stress integration tolerance. The results have demonstrated an increase in the analysis time when tighter stress integration tolerances are selected.

\section{Appendix A - Global matrices}

The definitions of the finite element matrices in the global equations of motion are as follows

$$
\mathbf{M}_{\mathbf{u}}=\int_{\Omega} \mathbf{N}_{\mathbf{u}}^{T} \rho \mathbf{N}_{\mathbf{u}} d \Omega
$$




$$
\begin{gathered}
\mathbf{M}_{\mathbf{w}}=\int_{\Omega}\left(\nabla \mathbf{N}_{\mathbf{p w}}\right)^{T}\left(\mathbf{k}_{g} \rho_{g}+\mathbf{k}_{w} \rho_{w}\right) \mathbf{N}_{\mathbf{u}} d \Omega \\
\mathbf{Q}_{\mathbf{c}}=\int_{\Omega} \mathbf{B}^{T}\left(1-S_{w}\right) \mathbf{m}_{\mathbf{p c}} d \Omega \\
\mathbf{Q}_{\mathbf{w}}=\int_{\Omega} \mathbf{B}^{T} \mathbf{m}_{\mathbf{p w}} d \Omega \\
\mathbf{M}_{\mathbf{C}}=\int_{\Omega}\left(\nabla \mathbf{N}_{\mathbf{p c}}\right)^{T} \mathbf{k}_{g} \rho_{g} \mathbf{N}_{\mathbf{u}} d \Omega \\
\mathbb{H}_{\mathrm{Ww}}=\int_{\Omega}\left(\nabla \mathrm{N}_{\mathrm{pw}}\right)^{T}\left(\mathbb{k}_{g}+\mathbb{k}_{w}\right)\left(\nabla \mathbf{N}_{\mathrm{pw}}\right) \mathrm{d} \Omega \\
\mathbb{H}_{\mathrm{cc}}=\int_{\Omega}\left(\nabla \mathrm{N}_{\mathrm{pc}}\right)^{T}\left(\mathbb{k}_{g}\right)\left(\nabla \mathbf{N}_{\mathrm{pc}}\right) d \Omega
\end{gathered}
$$

(16)
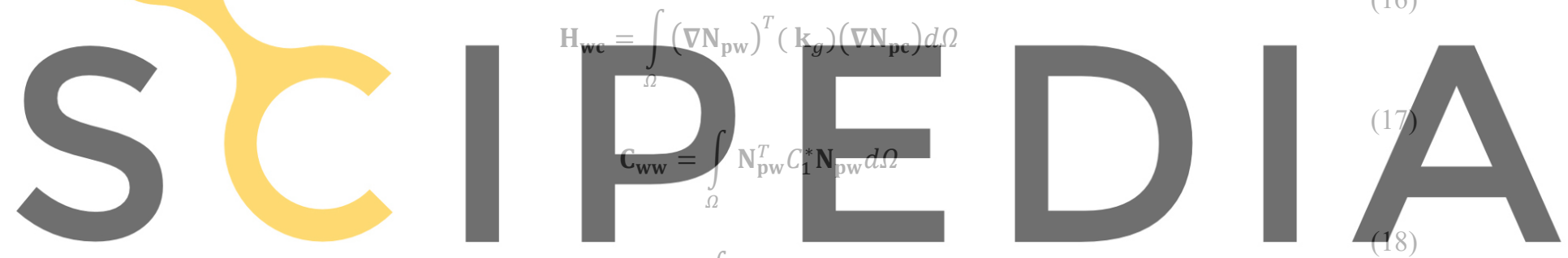

Register for free at https//www.scipedia.com to download the version without the watermark

$$
\begin{aligned}
& \mathbf{C}_{\mathbf{w c}}=\int_{\Omega} \mathbf{N}_{\mathbf{p w}}^{T} C_{3}^{*} \mathbf{N}_{\mathbf{p c}} d \Omega \\
& \mathbf{C}_{\mathbf{c w}}=\int_{\Omega} \mathbf{N}_{\mathbf{p c}}^{T} C_{3}^{*} \mathbf{N}_{\mathbf{p w}} d \Omega \\
& \mathbf{R}_{\mathbf{c}}=\int_{\Omega} \mathbf{B}^{T} C_{6} \mathbf{m N}_{\mathbf{p c}} d \Omega
\end{aligned}
$$

with $S_{g}$ as the degrees of saturation of the air phases. $C^{*}, C_{6}$, the vectors, and the imposed Dirichlet boundary conditions are given in [9]. The equation of the SWCC is obtained from $[3,22]$ as

$$
S_{w}^{\alpha}=S_{r w}+\left(S_{r a}-S_{r w}\right) *\left(\ln \left[\exp (1)+\left(\frac{p_{c}^{*}}{P^{\alpha}}\right)^{n_{x}^{\alpha}}\right]\right)^{-m_{x}^{\alpha}}(\alpha=w, d)
$$


where $P^{\alpha}$ denotes the air-entry value. $n_{x}^{\alpha}$ and $m_{x}^{\alpha}$ are the model parameters that control the slope of the SWCC. Also, $S_{r a}$ and $S_{r w}$ denote the maximum and minimum values of the residual degree of saturations. Table 2 shows the SWCC parameters used in the analyses.

Table 2: The SWCC parameters.

\begin{tabular}{ccccccc}
\hline$n_{x}^{d}$ & $m_{x}^{d}$ & $P^{d}(\mathrm{kPa})$ & $b^{d}$ & $\Omega^{\prime}$ & $S_{r a}$ & $S_{r w}$ \\
\hline 10 & 1.0 & 15.0 & 5 & 3.0 & 1 & 0 \\
\hline
\end{tabular}

\section{REFERENCES}

[1] Been, K. and Jefferies, M. G. A state parameter for sands. Géotechnique (1985) 35:99-112.

[2] Fischer, K. and Wriggers, P. Frictionless 2D contact formulations for finite deformations based on the mortar method. Computational Mechanics (2005) 36:226244.

[3] Fredlund, D. G. and Xing, A. Equations for the soil-water characteristic curve. Canadian geotechnical journal (1994) 31:521-532.

[4] Gallipoli, D., Gens, A., Sharma, R. and Vaunat, J. An elasto-plastic model for unsaturated soil incorporating the effects of suction and degree of saturation on mechanical behaviour. Géotechnique. (2003) 53:123-136.

[5] Ghorbani, J. Numerical simulation of dynamic compaction within the framework of unsaturated porous media, Doctor of Philosophy, Civil Engineering, University of Newcatsle, 2016.

[6] Ghorbani, J. and Airey, D. W. Modelling stress-induced anisotropy in multi-phase granular soils. Computational Mechanics (2021) 67:497-521.

[7] Ghorbani, J. and Airey, D. W., Some Aspects of Numerical Modelling of Hydraulic Hysteresis of Unsaturated Soils, in M. Hertz, ed., Unsaturated Soils: Behavior, Mechanics and Conditions, Nova Science Publishers, (2019).

[8] Ghorbani, J., Airey, D. W., Carter, J. P. and Nazem, M. Unsaturated soil dynamics: Finite element solution including stress-induced anisotropy. Computers and Geotechnics (2021) 133:104062.

[9] Ghorbani, J., Airey, D. W. and El-Zein, A. Numerical framework for considering the dependency of SWCCs on volume changes and their hysteretic responses in modelling elasto-plastic response of unsaturated soils. Computer Methods in Applied Mechanics and Engineering (2018) 336:80-110.

[10] Ghorbani, J., Nazem, M. and Carter, J. Application of the generalised- $\alpha$ method in dynamic analysis of partially saturated media. Computer Methods and Recent Advances in Geomechanics (2014)129-134.

[11] Ghorbani, J., Nazem, M. and Carter, J. Numerical modelling of multiphase flow in unsaturated deforming porous media. Computers and Geotechnics (2016) 71. 195206. 
[12] Ghorbani, J., Nazem, M. and Carter, J. P. Dynamic Compaction of Clays: Numerical Study Based on the Mechanics of Unsaturated Soils. International Journal of Geomechanics (2020) 20:04020195.

[13] Ghorbani, J., Nazem, M. and Carter, J. P. Numerical Study of Dynamic Soil Compaction at Different Degrees of Saturation, The Twenty-fifth International Ocean and Polar Engineering Conference, International Society of Offshore and Polar Engineers, (2016).

[14] Ghorbani, J., Nazem, M., Carter, J. P. and Airey, D. W. A numerical study of the effect of moisture content on induced ground vibration during dynamic compaction, 3rd International Conference on Performance Based Design in Earthquake Geotechnical Engineering, Vancouver, (2017).

[15] Ghorbani, J., Nazem, M., Carter, J. P. and Sloan, S. W. A stress integration scheme for elasto-plastic response of unsaturated soils subjected to large deformations. Computers and Geotechnics (2018) 94:231-246.

[16] Ghorbani, J., Nazem, M., Kodikara, J. and Wriggers, P. Finite element solution for static and dynamic interactions of cylindrical rigid objects and unsaturated granular soils. Computer Method in Applied Mechanics and Engineering (Accepted manuscript) (2021).

[17] Ghorbani, J., Noorzad, A. and Shahnazari, H. A smart increment technique and its application to a bounding surface model. Numerical Methods in Geotechnical Engineering (2014)45-47.

[18] Hallquist, J. NIKE2D: An implicit, finite-deformation, finite-element code for analyzing the static and dynamic response of two-dimensional solids, California Univ., Livermore (USA). Lawrence Livermore Lab., (1979).

[19] Kenneally, B., Musimbi, O. M., Wang, J. and Mooney, M. A. Finite element analysis of vibratory roller response on layered soil systems. Computers and Geotechnics (2015) 67:73-82.

[20] Kodikara, J., Islam, T. and Sounthararajah, A. Review of soil compaction: History and recent developments. Transportation Geotechnics (2018) 17:24-34.

[21] Laursen, T. A., Computational contact and impact mechanics: fundamentals of modeling interfacial phenomena in nonlinear finite element analysis, Springer Science \& Business Media, (2013).

[22] Manzanal, D., Pastor, M. and Merodo, J. A. F. Generalized plasticity state parameter-based model for saturated and unsaturated soils. Part II: Unsaturated soil modeling. International Journal for Numerical and Analytical Methods in Geomechanics (2011) 35:1899-1917.

[23] Paulmichl, I., Furtmüller, T., Adam, C. and Adam, D. Numerical simulation of the compaction effect and the dynamic response of an oscillation roller based on a hypoplastic soil model. Soil Dynamics and Earthquake Engineering (2020) 132: 106057.

[24] Pestana, J. M. and Whittle, A. Compression model for cohesionless soils. Géotechnique (1995) 45:611-631.

[25] Schrefler, B. A. The Finite Element Method in Soil Consolidation: (with Applications to Surface Subsidence), Doctor of Philosophy, University College of Swansea, 1984. 
[26] Wang, D., Bienen, B., Nazem, M., Tian, Y., Zheng, J., Pucker, T. and Randolph, M. F. Large deformation finite element analyses in geotechnical engineering. Computers and Geotechnics (2015) 65:104-114.

[27] Wriggers, P. and Zavarise, G. Computational contact mechanics. Encyclopedia of computational mechanics (2004). 